Article

\title{
Lean Manufacturing Tools Applied to Material Flow and Their Impact on Economic Sustainability
}

\author{
Jorge Luis García-Alcaraz ${ }^{1,2, * \mathbb{D}}$, José Roberto Díaz Reza ${ }^{2}$, Cuauhtémoc Sánchez Ramírez ${ }^{3} \mathbb{D}$, \\ Jorge Limón Romero ${ }^{4}$ (D), Emilio Jiménez Macías ${ }^{5}$ D, Carlos Javierre Lardies ${ }^{6}$ and \\ Manuel Arnoldo Rodríguez Medina ${ }^{2}$
}

check for updates

Citation: García-Alcaraz, J.L.; Díaz Reza, J.R.; Sánchez Ramírez, C.;

Limón Romero, J.; Jiménez Macías, E.; Lardies, C.J.; Rodríguez Medina, M.A. Lean Manufacturing Tools Applied to Material Flow and Their Impact on Economic Sustainability. Sustainability 2021, 13, 10599. https://doi.org/ $10.3390 /$ su131910599

Academic Editors: Gary Graham and Sebastian Kot

Received: 24 July 2021

Accepted: 21 September 2021

Published: 24 September 2021

Publisher's Note: MDPI stays neutral with regard to jurisdictional claims in published maps and institutional affiliations.

Copyright: (C) 2021 by the authors. Licensee MDPI, Basel, Switzerland. This article is an open access article distributed under the terms and conditions of the Creative Commons Attribution (CC BY) license (https:/ / creativecommons.org/licenses/by/ $4.0 /)$.
1 Department of Industrial Engineering and Manufacturing, Autonomous University of Ciudad Juárez, Ciudad Juárez 32310, Chihuahua, Mexico

2 Department of Industrial Engineering, Tecnológico Nacional de Mexico/I.T. Ciudad Juárez, Ciudad Juárez 32500, Chihuahua, Mexico; roberto.dr01@itcj.edu.mx (J.R.D.R.); manuel_rodriguez_itcj@yahoo.com (M.A.R.M.)

3 Division of Research and Postgraduate Studies, Tecnológico Nacional de Mexico/Instituto Tecnológico de Orizaba, Orizaba 94320, Veracruz, Mexico; csanchezr@ito-depi.edu.mx

4 Faculty of Engineering, Desing and Architecture, Universidad Autónoma de Baja California-Campus Ensenada, Ensenada 22860, Baja California, Mexico; jorge.limon@uabc.edu.mx

5 Department of Electric Engineering, University of La Rioja, 26006 Logroño, La Rioja, Spain; emilio.jimenez@unirioja.es

6 Department of Mechanical Engineering, University of Zaragoza, 50009 Zaragoza, Aragon, Spain; sabicjl@unizar.es

* Correspondence: jorge.garcia@uacj.mx; Tel.: +52-656-6884843 (ext. 5433)

\begin{abstract}
This paper presents a second-order structural equation model that analyzes three lean manufacturing tools associated with material flow, such as 5S, SMED, and continuous flow related to economic sustainability. The variables relate to each other through six hypotheses, tested with 169 responses to a questionnaire applied to the Mexican maquiladora industry, using the partial least squares technique and $95 \%$ confidence to estimate direct, the sum of indirect, and total effects. In addition, an analysis with conditional probabilities appears to determine how low and high implementation levels in independent variables affect the dependent variables' occurrence. Findings indicate that $5 \mathrm{~S}$ is a lean manufacturing tool with the most increased direct effects on SMED and continuous flow. Additionally, values indicate that SMED is essential to maintain continuous flow in production lines and is vital for economic sustainability due to the time reduction in setup.
\end{abstract}

Keywords: 5S; SMED; continuous flow; economic sustainability

\section{Introduction}

Market and supply chains (SC) are globalized, and sometimes the cost associated with SC represents $70 \%$ [1]. This is because a product may integrate components from different countries; some parts are assembled in another and sold in a different one, making them complex material flows [2]. In addition, some companies seek to be geographically close to their customers, so they establish subsidiaries in other countries to minimize the distance to the final market.

In the specific case of Mexico, given its proximity to the United States of America (USA) as one of the biggest world markets, some foreign companies establish assembly centers in the north. They also take advantage of low labor costs and high human resources training and tariff preferences due to trade agreements among those countries, including Canada [3].

Those companies are established in Mexico but have their headquarters in other countries, depending administratively on them, and traditionally, they are called maquiladoras [4]. There are currently 5171 companies of this type in Mexico, 493 in Chihuahua state, 
and, specifically, 329 are established in Ciudad Juarez. This industrial sector is essential regionally due to its economic and social implications and represents an academic and scientific research area due to those factors [5].

The maquiladora industry (MI) generates 2,702,116 direct jobs nationwide in Mexico, 484,809 in Chihuahua state, and 321,824 in Ciudad Juarez. In addition, as of January 2021, a total of USD 13,647 and 17,170 million for imports and exports, respectively, had been registered nationwide, of which 1638 and 2060 million correspond to imports and exports of companies located in Chihuahua state and, precisely, 1296 and 1631 correspond to Ciudad Juarez, which indicates the economic importance of that industrial sector [5]. Those values indicate the high volume of raw and finished products moved across the Mexican border and denote SC importance.

MI established in Mexico are companies with highly technified production systems, bringing methodologies, techniques, and tools to production lines. One methodology widely used in MI is lean manufacturing (LM), integrated by various widely studied tools [6], focusing on waste reduction.

LM tools integrate tools into primary and essential, which are the basis for all others. Then, there are LM tools associated with the production system's material flow, quality improvement, and human resources optimization. All these LM tools minimize waste or activities that do not add value to the product but cost customers [7].

The LM tools associated with the material flow in a production system aim to keep an internal SC with acceptable performance indicators. This category's most relevant LM tools are 5S, Single-Minute Exchange of Die (SMED), and continuous flow. 5S is a tool aimed at dismissing waste, organizing and improving the workplace, and preventing accidents with norms and standards [6,7]. At the same time, SMED reduces waste in a production system based on ensuring a tool changeover time of single-digit minutes [8]. However, those two LM tools focus on keeping a continuous material flow with a small lot size to improve financial income by customizing products.

This paper aims to find the relationship between those three LM tools and the economic sustainability for the MI, given the economic importance they have for the Mexican MI, specifically for Ciudad Juarez.

\section{Literature Review}

\subsection{LM and Sustainability}

The LM implementation offers several benefits to companies, and Melton [9] was the first interested in associating it with companies' income. Recently, Islam [10] indicates that LM applies to the entire SC and reviews which partners gain better economic benefits. So, one important research area is the relationship that LM has with a company's financial sustainability.

The relationship between LM and sustainability is of academic interest; for example, Saetta and Caldarelli [11] relate LM for green production; Bai et al. [12] indicate that investing in LM tools applications generates environmental and operational benefits. However, LM and sustainability are not applied in isolation; for example, Cherrafi et al. [13] aggregate six sigma to that equation; Ghobadian et al. [14] integrate innovation, Varela et al. [15] recently combined industry 4.0, and finally, Burawat [16] added transformational leadership. In conclusion, LM is associated with sustainability together with other managerial or operative methodologies.

All prior research analyzes sustainability as a generic concept, and it has three main pillars: economic, environmental, and social. Additionally, in several recent studies, sustainability focuses only on environmental aspects, ignoring the social and economic ones. However, according to Kalyar et al. [17], the main goal in LM is to generate financial income for the company.

One of the initial studies associating LM with firm performance was reported by Shah and Ward [18] almost two decades ago. Other studies, such as Yang et al. [19], integrated other variables, such as environmental impact. However, it is not until Fullerton et al. [20] 
that a direct effect regarding the role of LM in the accounting and financial performance of the company is analyzed.

\subsection{Specific LM Tools and Sustainability}

Other studies refer to specific LM tools implementations, which are reductionist because LM is a set of managerial tools. For example, Aquilani et al. [21] and Green et al. [22] explore total quality management (TQM) impact on sustainability; Yazdi et al. [23] analyze overall equipment efficiency (OEE). In addition, Reis et al. [24] study total productive maintenance (TPM) and how it helps reduce the loss of raw materials due to deficiencies in machine calibration.

Additionally, Setiawan et al. [25] proposes a managerial model to associate $5 \mathrm{~S}$ to sustainability in Indian manufacturing companies and Xu et al. [26] report the waste tool from LM to reduce the environmental impact in Chinese factories.

\subsection{LM and Sustainability in the Maquiladora Industry}

Research regarding LM tools in the MI is scarce in Mexico, even for the industrial, economic, and social importance, since several studies have focused on other research lines, such as SC. For example, Jun et al. [27] study TQM practices in MI as an antecedent of employee loyalty and satisfaction; García et al. [28] explore the JIT application and relate it to financial performance.

Likewise, Díaz-Reza et al. [29] analyze how MI applies SMED and how it has generated operational benefits and ignoring the economic income or cost reduction. Additionally, while García-Alcaraz et al. [30] report how MI applies information and communication technologies (ICT) to SC and associate their critical success factors to the benefits obtained. Finally, Morales-García et al. [31] report the effect of TPM and OEE in social sustainability, reducing accidents.

However, sustainability in MI has also been studied in an isolated way. For example, Velázquez et al. [32] report an overview of sustainability in the MI in Mexico, specifically in Sonora state; Munguía Vega et al. [33] report the integration of ergonomics and sustainability, focusing only on social sustainability.

However, Hadjimarcou et al. [34] indicate that sustainability and education in workers are the pillars in six strategies for a maquiladora's success. Cruthirds et al. [35] point out that Mexican maquiladoras have outstanding sustainability and responsive practices to gain financial income. In other words, LM practices are associated with the companies' sustainability since if they do not obtain an economic benefit, their implementation in the production lines is out of justification.

Currently, there are some studies relating LM to economic sustainability; for example, Chetthamrongchai and Jermsittiparsert [36] look for this relationship in the pharmaceutical industry in Thailand, while Fullerton and Wempe [37] do so in the United States of America. So, it is observed that research is required to relate the LM tools applied in the Mexican MI with economic benefits gained, since current studies are scarce or focus on analyzing only one LM tool with the overall performance.

This study aims to investigate a group of three LM tools associated with the material flow throughout the production system: 5S, SMED, and continuous flow, which are related to the economic sustainability they offer. Those LM tools are selected because SC in the MI is one of the most important, mainly due to the high importation and exportation rates in that industrial sector [38].

Additionally, tools such as SMED are associated with safety in workplaces because sometimes changeover occurs when machines are operating [39]. Additionally, RodríguezMéndez et al. [40] report that SMED is associated with other LM tools, such as JIT and facilitating on-time deliveries. Regarding 5S, Singh and Ahuja [41] indicate that this LM tool is associated directly with manufacturing performance, and it is a vital tool that generates discipline and high standards in the workplace. 
The novelty of this research is that it integrates three LM in only one model and relates them to economic sustainability using a statistical technique, quantifying their relationship. Additionally, sensitivity analysis indicates how high and low LM tool implementation levels affect the MI's economic income, facilitating supply chain managers' decision-making to focus resources on specific activities.

The article is structured as follows. After this introduction, section two presents a literature review about the four variables analyzed and justifies their relationships; the third section presents the methodology followed to meet the established objective; the fourth section presents the results. Finally, the fifth section presents the conclusions and industrial implications of the results found.

\section{Hypotheses}

\section{1. $5 S$}

The $5 S$ methodology is a work philosophy that gives order and meaning to work dynamics, addressing workplace disorganization situations. The $5 \mathrm{~S}$ are Seiri, Seiton, Seiso, Seiketsu, and Shitsuke (classification, organization, cleaning, standardization and improvement) [42]. In industrial practice, $5 S$ focuses on improving conditions at workstations and employee habits. If the tools and equipment required to perform an activity are always classified, organized, clean, and ready to use, that becomes a custom or standard, the primary basis of $5 S$. As a consequence, the company obtains operational and productivity benefits [43].

However, reports indicate the extension of the lean $5 \mathrm{~S}$ to $6 \mathrm{~S}$ to ensure occupational safety and health [44], and some applications are reported by Misiurek and Misiurek [45] and Gnanaguru et al. [46]. However, recent studies report a new evolution, the 7S methodology, adding Spirit for employee engagement across all manufacturing levels [47,48].

In this research, the $5 S$ implementation level in the $\mathrm{MI}$ is assessed by five items associated with employees' training for understanding the methodology: establishing cleaning procedures and standardizing the tools used, conducting audits to maintain those standards, giving recognition to employees for achievements, in addition to documenting the processes. In this research, it is assumed that if there are tools in place to carry out every activity, then the flow of the productive system is faster since it is easy to know where they are, and operations require low time.

\subsection{Single-Minute Exchange of Die (SMED)}

SMED is a response to the need to reduce production batches' size and looks to switch quickly from one product to another [49]. Traditionally, manufacturers prefer to assemble large quantities and prorate the setup cost over a high number of units. Otherwise, the entire fee associated with setup must be associated with few parts, increasing costs and reducing the market share [8].

SMED separates the time required to perform changeover, to prepare tools and machines, for internal preparation, and for external preparation. SMED divides all activities into internal and external. The internal activities are performed when the machines are working, while external activities need to stop them [50]. The central idea is to complete as many activities as possible when the machines are operating.

This research measures the SMED implementation level by seven items associated with the production system's flexibility for responding to demand adjustments. In addition, changeover with less than $10 \mathrm{~min}$, if there are improvement groups, the ability to manufacture different products on a production line, and the percentage of orders delivered on time is investigated, among other things.

In this research, it is assumed that if the tools are tidy, clean, and in good condition in a workplace, then changeovers from one product to another should be fast because no time is wasted in locating them or preparing them to be used [51]. In addition, such clean workplaces avoid accidents that hinder the material flow along the production line, giving flexibility to the entire process [52]. Therefore, the following hypothesis is proposed: 
Hypothesis 1 (H1). The implementation of $5 S$ in the maquiladora industry has a direct and positive effect on SMED.

\subsection{Continuous Flow (COF)}

In its ideal state, COF means that products are processed and transported directly from one stage of the production process to the next, one piece at a time, representing the optimal order size. Thus, each step of the production process works only on the part that the next one needs, just before the next one needs it. COF aims to eliminate massive inventories, delay deliveries, and ensure more market coverage since customized products can be manufactured.

To measure COF implementation in the MI, we observe whether production is organized as families, the supplier responsiveness, the tack time for activities and products, the amount of inventory in the process, and whether there are bottlenecks.

The MI must have clean, tidy work centers with tools in place to achieve the above, which facilitates quick changes that translate into a COF of parts [40]. Studies such as those by Piñeiro et al. [53] indicate that the 5S philosophy application in pharmaceutical production lines helps to decrease uncertainty in COF, so the following hypothesis is proposed:

Hypothesis 2 (H2). The implementation of $5 S$ in the maquiladora industry has a direct effect on continuous flow.

For the MI to be flexible and have a COF, it requires a great capacity to respond to customers and make changes quickly or in the shortest possible time [54], as this gives them the ability to adjust the production lines to generate different products, so the following hypothesis is proposed:

Hypothesis 3 (H3). The implementation of SMED in the maquiladora industry has a direct effect on continuous flow.

\subsection{Economic Sustainability (ES)}

The LM application in MI is not fortuitous since managers expect to obtain benefits from their implementation, and the most important is ES. ES is a globalized term that includes financial and accounting aspects, which are undoubtedly essential, and integrates aspects associated with sustainability, where the optimization of available resources is sought [55]. In conclusion, ES means implementing profitable strategies and practices that improve the rational use of resources while maximizing the benefits provided by companies [56].

To measure ES in the MI, it is necessary to quantify the reduction in production costs [57], new product design, and energy consumption [58], inventory management, rejection of production orders, raw materials entering the production process, and waste generated from processing [59].

The ES may be due to various LM tools implemented in the production lines. Mohan, Sharma, and Lata [60] mention that workstations with installed programs such as $5 \mathrm{~S}$ have increased efficiency, productivity, and financial performance. Additionally, Jugraj Singh and Inderpreet Singh [61] indicate that 5S, combined with quality programs, has supported a sustainable performance because these tools are the most important of LM. Therefore, the following hypothesis is proposed:

Hypothesis 4 (H4). The implementation of $5 S$ in the maquiladora industry has a direct effect on economic sustainability.

Another source of ES is SMED because it improves operating rates on production lines combined with other techniques. For example, Tekin, Arslandere, Etlioğlu, Koyuncuoğlu, and Tekin [8] indicate that SMED and Jidoka generate greater flexibility to production 
processes, reducing the idle time in machines due to product changes, and that means cost reduction. In turn, Díaz-Reza, García-Alcaraz, Martínez-Loya, Blanco-Fernández, Jiménez-Macías, and Avelar-Sosa [29] indicate that SMED has allowed MI to generate a greater diversity of products for final customers, representing the best market coverage and monetary income. Therefore, the following hypothesis is proposed:

Hypothesis $\mathbf{5}$ (H5). The implementation of SMED in the maquiladora industry has a direct effect on economic sustainability.

Although mass production was efficient for a long time, it had the disadvantage of having little variety in products, but low production costs. These problems have been solved so that the ideal is to have a production order for a single product, as proposed by the COF, which gives more market coverage with customized products. The benefits of having a COF are that each product is produced only when required, minimizing inprocess inventories and storage [54]. Additionally, Vitayasak et al. [62] indicate that a machine's layout contributes to having a COF with a shorter waiting time for material, and an improved relationship with the customer strengthens the economic sustainability. Therefore, the following hypothesis is proposed:

Hypothesis 6 (H6). The implementation of continuous flow in the maquiladora industry has a direct effect on economic sustainability.

Figure 1 graphically presents the relationships between the analyzed variables that have been established as hypotheses. Observe the arrow direction to identify the independent variable where the arrow begins and the dependent variable where the arrow ends. In this proposed model, we assumed that all effects are positive. The following paragraphs describe the methodology for testing the proposed hypotheses.

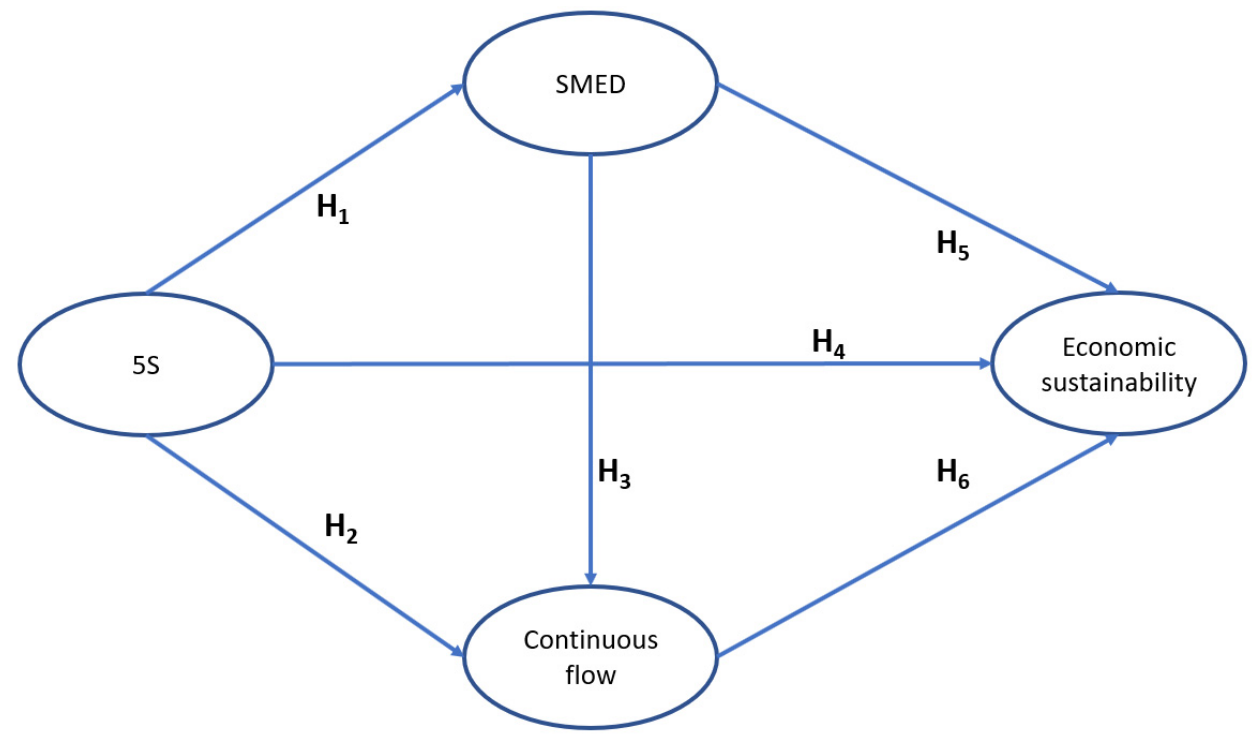

Figure 1. Proposed Model.

\section{Methodology}

\subsection{Questionnaire Design}

To validate the hypotheses in Figure 1, information from the MI is required, so a questionnaire is designed based on a literature review conducted in databases such as Scopus, ScienceDirect, Springer, Ingenta, and others. The keywords in the search refer to the four variables analyzed: 5S, SMED, continuous flow, and economic sustainability. The literature review aims to identify activities indicating LM tool implementation levels 
and parameters measuring economic sustainability [63]. This process represents a rational validation.

However, since the questionnaire is designed using a literature review process, obtaining items used by other authors in different countries and industrial sectors, a judge's validation is applied to adapt it to the Mexican MI [64]. The judges were three academic and ten industrial managers. Judges had to assess whether the items in the questionnaire had sufficiency, clarity, coherence, and relevance. After three rounds with judges, a final questionnaire was defined.

Based on the literature review and judges' validation, a first questionnaire draft is constructed, divided into three sections. The first section obtains demographic information from respondents, the industrial subsector, years of experience in current job positions, and gender. The second section contains items related to each of the three LM tools analyzed. In this case, the $5 S$ are integrated by six items, SMED by seven items, and continuous flow by six items. Finally, the last section contains seven items associated with economic sustainability and how the MI measures the LM benefits.

The final survey is available from Morales García et al. [65]. The items for SMED are obtained from Díaz-Reza, García-Alcaraz, Martínez-Loya, Blanco-Fernández, JiménezMacías, and Avelar-Sosa [29], 5S are integrated from Setiawan, Salleh, Ariff, Rahman, Mohamad, Sulaiman, Zaini, and Ito [25], continuous flow is integrated from Amelec [66] and Rodríguez-Méndez, Sánchez-Partida, Martínez-Flores, and Arvizu-BarrÓn [40], and finally, economic sustainability is integrated from Girón et al. [67].

Items must be answered on a 6-point Likert scale, where one indicates that the activity is not performed, or the benefit is not obtained. In contrast, six indicates that the activity is always performed, or the benefit is always obtained.

\subsection{Questionnaire Administration}

The questionnaire is applied to managers, engineers, and supervisors of production lines since they are the ones who know about the LM tools' implementation and the benefits obtained. The survey is applied to the MI established in Ciudad Juarez in Mexico. As previously stated, MI represents the primary industrial sector in that region, and it has a high social and economic impact [68].

Currently, there are 328 MIs in Ciudad Juárez, and that is the target population. The automotive sector accounts for $32 \%$, electronics for $29 \%$, medical for $7 \%$, plastics and metals for $12 \%$, call centers for $3 \%$, packaging for $8 \%$, and miscellaneous for $9 \%$ [69]. This MI is occupying $67 \%$ of the region's active direct labor force, followed by the business, personal, and home services sectors with only $9 \%$, indicating indirectly associated enterprises [70].

The questionnaire is uploaded into a specialized webpage for online application since access to the MI is limited due to the COVID-19 pandemic. An email is sent to all potential respondents attaching the electronic link to the questionnaire. If after 15 days, no response to the questionnaire is obtained, a second invitation is sent, and if after three attempts, no reply is received, then that case is discarded.

\subsection{Information Gathering and Debugging}

The platform stays open to receive information from 1 October to 15 December 2020. After that date, a database in Excel format is downloaded and analyzed in SPSS v.25 software to perform a debugging process that includes the following tasks:

- $\quad$ Standard deviation (SD) estimation. If SD values are less than 0.5 , then that case is discarded as a non-committed respondent.

- Outlier identification. Each item is standardized and absolute values greater than or equal to 4 are considered extreme values and replaced by the median.

- Missing values identification. The median replaces missing values if the average is less than $10 \%$; otherwise, that case is eliminated. 


\subsection{Latent Variable Validation}

Before integrating latent variables in the model, all of them are validated according to the following indices:

- $\mathrm{R}^{2}$ and adjusted $\mathrm{R}^{2}$ for parametric predictive validation, which must be greater than 0.02 [71].

- Cronbach's alpha and composite reliability index for internal consistency, which must be greater than 0.7 [72].

- The average variance extracted (AVE) for discriminant validity, which must be greater than 0.5 [72].

- Variance inflation factor (VIF) for measuring collinearity between variables and common method bias (CMB), which must be less than 3.3 [73].

- $\quad \mathrm{Q}^{2}$ for nonparametric predictive validation, which should be similar to $\mathrm{R}^{2}$ [71].

Here, it is essential to note that some indexes for latent variables are iteratively estimated, for example, the Cronbach's alpha and the VIF, until obtaining an acceptable value, and some items are discarded from the analysis to improve those validity indexes.

\subsection{Descriptive Analysis of the Items}

The items that remain in the latent variables after being validated are analyzed as follows to know the central and dispersion measures in univariate analysis [74]:

- The median of the items is obtained as a measure of central tendency, given that the data are on an ordinal scale. High median values indicate that the item's activity is always executed, or the benefit is always obtained. Low values indicate that the activity is not achieved, or the benefit is not obtained.

- The interquartile range of the items is obtained as a measure of dispersion, which is the difference between the third and first quartile. Low values indicate a high consensus among responders.

\subsection{Structural Equation Model}

The structural equation modeling (SEM) technique is selected to test the hypotheses proposed in Figure 1; specifically, the partial least squares (PLS) method, based on the linear regression technique, is used to estimate standardized dependence values between latent variables. PLS is integrated into the WarpPLS v. $7^{\circledR}$ software [75], and it applies when there are no normally distributed data, obtained on an ordinal scale or with a small sample [71].

The analysis is performed with $95 \%$ confidence. Before the model is interpreted, specific efficiency and quality indexes of the model are validated, such as the following [71]:

- $\quad$ Average path coefficient (APC) to measure the global significance of the direct effect. The $\mathrm{p}$-value associated must be less than 0.05 .

- $\quad$ Average $\mathrm{R}^{2}$ (ARS) and average adjusted $\mathrm{R}^{2}$ (AARS) to measure the variance explained by independent variables on dependent variables, and the associated p-value must be less than 0.05 .

- $\quad$ Average block VIF (AVIF) and average full collinearity VIF (AFVIF) to measure general collinearity, which should be less than 3.3.

- Tenenhaus GoF index (GoF) measures the data to the model and should be greater than 0.36 .

Three types of effects are measured. First, direct effects are used to test the hypothesis in Figure 1. A standardized $\beta$ value is obtained using PLS for each relationship between variables and associated with a p-value that must be less than 0.05 [76]. The null hypothesis tested is $\beta=0$, versus the alternative hypothesis that $\beta \neq 0$. If it is statistically proven that $\beta=0$, then it is concluded that there is no relationship between the variables; otherwise, if it is proven that $\beta \neq 0$, there is a relationship.

The second one is called indirect effect and occurs through third variables named mediators and are of particular interest when the direct effects are not statistically significant. In this case, the total sum of indirect effects is reported with their associated p-value. 
Finally, the third one is the total effect, which represents the sum of direct and indirect effects.

Additionally, an $\mathrm{R}^{2}$ value is reported with latent dependent variables in the model as a measure of variance explained by all independent variables, contributing an effect size (ES). So, for every direct, indirect, and total effect, an ES is reported.

\subsection{Sensitivity Analysis}

Since PLS performs its calculations based on standardized values, then probabilities can be calculated when the different variables occur at low $\mathrm{P}(Z<-1)$ and high $\mathrm{P}(Z>1)$ scenarios [71]. Probabilities are calculated for the variables occurring in isolation in high and low scenarios, jointly in a combination of scenarios (represented by \&) and the conditional probability of the dependent variable occurring, given that the dependent variable has occurred (represented by IF).

Specifically, this paper reports a probability of joint occurrence of two variables in different scenarios, such as $\mathrm{P}\left(Z_{\mathrm{i}}>1\right) \cap \mathrm{P}\left(\mathrm{Z}_{\mathrm{d}}>1\right), \mathrm{P}\left(\mathrm{Z}_{\mathrm{i}}>1\right) \cap \mathrm{P}\left(\mathrm{Z}_{\mathrm{d}}<-1\right), \mathrm{P}\left(\mathrm{Z}_{\mathrm{i}}<-1\right) \cap \mathrm{P}\left(\mathrm{Z}_{\mathrm{d}}>1\right)$, and $\mathrm{P}\left(Z_{\mathrm{i}}<-1\right) \cap \mathrm{P}\left(\mathrm{Z}_{\mathrm{d}}<-1\right)$, as well as the conditional probability for $\mathrm{P}\left(\mathrm{Z}_{\mathrm{d}}>1\right) / \mathrm{P}\left(\mathrm{Z}_{\mathrm{i}}>1\right)$, $\mathrm{P}\left(\mathrm{Z}_{\mathrm{d}}>1\right) / \mathrm{P}\left(\mathrm{Z}_{\mathrm{i}}<1\right), \mathrm{P}\left(\mathrm{Z}_{\mathrm{d}}<-1\right) / \mathrm{P}\left(\mathrm{Z}_{\mathrm{i}}>1\right)$ and $\mathrm{P}\left(\mathrm{Z}_{\mathrm{d}}<-1\right) / \mathrm{P}\left(\mathrm{Z}_{\mathrm{i}}<-1\right)$, where $\mathrm{Z}_{\mathrm{i}}$ represents a standardized value for an independent variable and $Z_{d}$ for a dependent variable; -1 represents a low scenario for a variable and 1 a high scenario.

\section{Results}

\subsection{Descriptive Analysis of the Sample and Items}

One hundred and seventy-eight responses to the questionnaire were collected from 433 emails sent, giving a response rate of $41.10 \%$; however, nine were discarded for not complying with the inclusion principles, so only 169 were analyzed (57 women and 112 men). Regarding experience in the position, 44 had 2 to 3 years, 26 had 3 to 5 years, 75 had 5 to 10 years, and 24 had more than ten years. The final dataset analyzed is available from Martínez Hernández and García Alcaraz [77].

Table 1 illustrates the respondents' industrial sectors and job positions, where it can be seen that the automotive and electrical sectors were the ones that participated the most, followed by medical and electronic. In this research, the machining, logistics, and electronic industrial sector have low participation. However, this sector participation is proportional to the current number of MI established in Ciudad Juarez, Mexico.

Table 1. Descriptive analysis of the sample.

\begin{tabular}{cccccc}
\hline Industrial Sector & Manager & Engineer & Supervisor & Total & Percentage \\
\hline Automotive & 8 & 28 & 39 & 75 & 44.37 \\
Medical & 3 & 16 & 21 & 40 & 23.66 \\
Electric & 6 & 17 & 12 & 35 & 20.71 \\
Electronic & 0 & 4 & 5 & 9 & 5.32 \\
Logistic & 0 & 2 & 5 & 7 & 4.14 \\
Machining & 0 & 1 & 2 & 3 & 1.77 \\
Total & 17 & 68 & 81 & 169 & 100 \\
\hline
\end{tabular}

Additionally, regarding the job position, it can be seen that supervisors and engineers were the most responsive, with 81 and 68 , respectively, and representing $81.16 \%$. This participation rate indicates that information analyzed in this research comes from persons in production lines every day, with experience in their job, and their opinions are reliable.

Table 2 illustrates the descriptive analysis of the items, where the median as a measure of central tendency and the interquartile range as a measure of dispersion are shown. The items are ordered in descending way according to the median. According to those values, the most critical item for $5 \mathrm{~S}$ is to have standards regarding how to carry out every piece of work, and the second most is to have documented methods and procedures. That indicates 
that Seiton and Seitketsu (order and standardization) are widely supervised when 5S is applied in MI.

Table 2. Descriptive analysis of the items.

\begin{tabular}{|c|c|c|}
\hline $5 S$ & Median & IR \\
\hline There is a standard of how the work area should be maintained. & 5.11 & 1.60 \\
\hline Methods are documented and standardized through procedures. & 5.03 & 1.70 \\
\hline The achievements obtained after implementing the 5Ss are exposed. & 4.78 & 1.86 \\
\hline \multicolumn{3}{|l|}{ SMED } \\
\hline $\begin{array}{l}\text { When using SMED, techniques such as DMAIC are followed to } \\
\text { implement the methodology successfully. }\end{array}$ & 4.69 & 1.73 \\
\hline There is awareness of the cost of having idle equipment. & 4.59 & 1.62 \\
\hline Improvement groups are in place to reduce idle time on machinery. & 4.54 & 1.71 \\
\hline \multicolumn{3}{|l|}{ Continuous flow } \\
\hline The production process is organized on product families & 4.82 & 1.73 \\
\hline Bottlenecks are identified. & 4.79 & 1.89 \\
\hline $\begin{array}{c}\text { Continuous improvement groups are in place to help eliminate } \\
\text { unnecessary operations. }\end{array}$ & 4.64 & 1.95 \\
\hline Material suppliers respond quickly & 4.46 & 1.77 \\
\hline The takt time of the production line is known and followed. & 4.46 & 1.63 \\
\hline \multicolumn{3}{|l|}{ Economic sustainability } \\
\hline There is a reduction in the cost of material acquisition. & 4.73 & 1.74 \\
\hline Economic benefits have increased in the last two years. & 4.68 & 1.77 \\
\hline Sales have increased in the last two years. & 4.65 & 1.77 \\
\hline There is a reduction in the cost of energy utilization. & 4.62 & 1.91 \\
\hline
\end{tabular}

The critical item for SMED is to follow a DMAIC procedure for its implementation because SMED aims to reduce the changeover times and to create awareness regarding the cost due to idle machinery. Regarding continuous flow, the most important is to have a production process organized on product families and identify the bottleneck as a barrier to material flow. Finally, the most important for economic sustainability is cost reduction due to raw material acquisition and increasing sales.

\subsection{Latent Variable Validation}

Table 3 shows the validation indexes for latent variables. All variables meet the cut-off values established in the methodology, so they are integrated into the structural equation model. According to $\mathrm{R}^{2}$ and adjusted $\mathrm{R}^{2}$, dependent variables have enough parametric predictive validity, composite reliability, and Cronbach's alpha indicates adequate internal and construct validity. Additionally, AVE indicates good convergent validity and VIF suggests the absence of $\mathrm{CMB}$ and collinearity problems. Finally, $\mathrm{Q}^{2}$ demonstrates that there is acceptable nonparametric predictive validity in all dependent latent variables.

Table 3. Latent variable validation.

\begin{tabular}{cccccc}
\hline Index & 5S & SMED & COF & ES & Cutoff \\
\hline $\mathrm{R}^{2}$ & & 0.327 & 0.503 & 0.463 & $>0.02$ \\
Adjusted R ${ }^{2}$ & & 0.323 & 0.497 & 0.453 & $>0.02$ \\
Composite reliability & 0.929 & 0.923 & 0.886 & 0.923 & $>0.7$ \\
Cronbach's alpha & 0.885 & 0.875 & 0.838 & 0.889 & $>0.7$ \\
AVE & 0.813 & 0.800 & 0.609 & 0.751 & $>0.5$ \\
Full collinearity VIF & 1.629 & 2.178 & 2.239 & 1.831 & $<3.3$ \\
$\mathrm{Q}^{2}$ & & 0.325 & 0.502 & 0.471 & Similar to R ${ }^{2}$ \\
\hline
\end{tabular}




\subsection{Structural Equation Model}

Before interpreting the model, its efficiency indexes are calculated and listed below. According to those values, the model fulfills the cut-off value, so it is interpreted. APC indicates that the $\beta$ values are adequated on average, and there are relationships among variables. ARS and AARS indicate adequated predictive validity in the model; AVIF and AFVIF indicate the absence of collinearity and the CMB problem. Finally, the GoF shows that the data have a good fit for the model.

- $\quad$ Average path coefficient $(\mathrm{APC})=0.356, \mathrm{P}<0.001$

- $\quad$ Average R-squared (ARS) $=0.431, \mathrm{P}<0.001$

- $\quad$ Average adjusted R-squared (AARS) $=0.424, \mathrm{P}<0.001$

- $\quad$ Average block VIF (AVIF) $=1.707$, acceptable if $\leq 3.3$

- $\quad$ Average full collinearity VIF (AFVIF) $=1.969$, acceptable if $\leq 3.3$

- $\quad$ Tenenhaus $\mathrm{GoF}(\mathrm{GoF})=0.566$, large $\geq 0.36$

Figure 2 illustrates the model evaluated, where the $\beta$ values and the associated $p$ values are shown for every relationship. However, $R^{2}$ is illustrated for latent dependent variables.

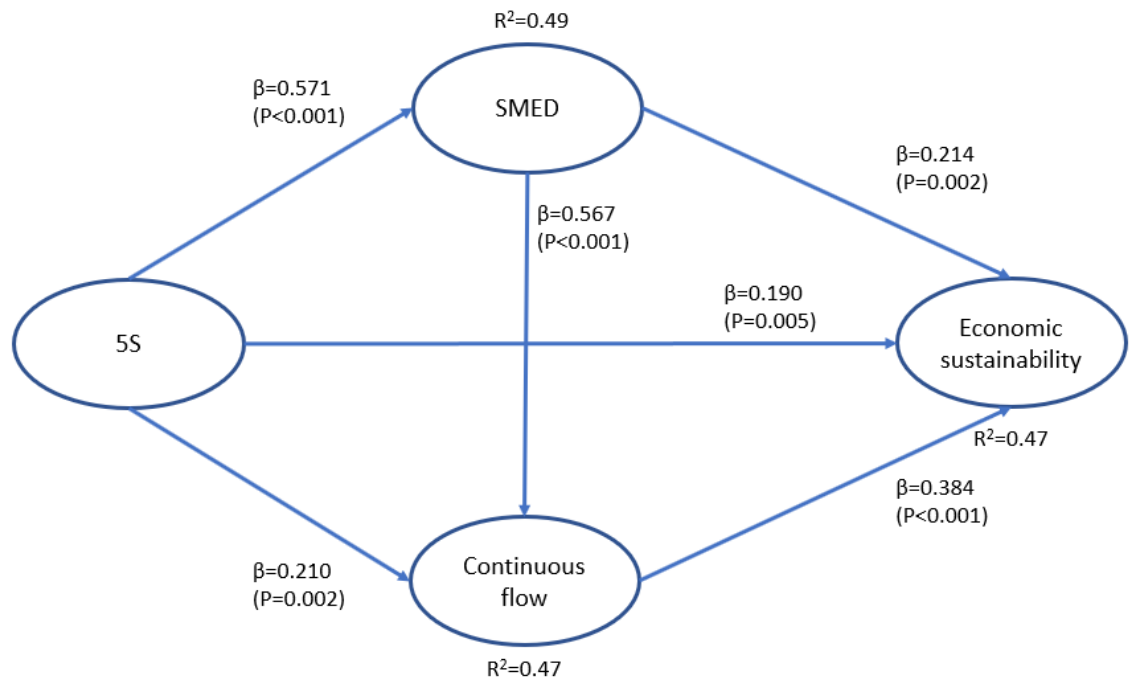

Figure 2. Evaluated model.

\subsubsection{Direct effect}

Figure 2 illustrates all the direct effects, and it is observed that all of them are statistically significant since the $p$-value associated with each $\beta$ value is less than 0.05 . Table 4 summarizes the relationships between variables, the hypothesis they represent, the $\beta$-values, their $p$-value, and the conclusion for them.

Table 4. Conclusions regarding the direct effects and hypotheses.

\begin{tabular}{ccccc}
\hline Hypothesis & Relationship & $\boldsymbol{\beta}$ & p-Value & Conclusion \\
\hline $\mathrm{H}_{1}$ & $5 \mathrm{~S} \rightarrow \mathrm{SMED}$ & 0.571 & $<0.001$ & Supported \\
\hline $\mathrm{H}_{2}$ & $5 \mathrm{~S} \rightarrow \mathrm{COF}$ & 0.210 & $=0.002$ & Supported \\
\hline $\mathrm{H}_{3}$ & $\mathrm{SMED} \rightarrow \mathrm{COF}$ & 0.567 & $<0.001$ & Supported \\
\hline $\mathrm{H}_{4}$ & $5 \mathrm{~S} \rightarrow \mathrm{ES}$ & 0.190 & $=0.005$ & Supported \\
\hline $\mathrm{H}_{5}$ & $\mathrm{SMED} \rightarrow \mathrm{ES}$ & 0.214 & $=0.002$ & Supported \\
\hline $\mathrm{H}_{6}$ & $\mathrm{COF} \rightarrow \mathrm{ES}$ & 0.384 & $<0.001$ & Supported \\
\hline
\end{tabular}


Interpreting the $\mathrm{H}_{1}$ as an example, findings indicate that there is enough statistical evidence to declare that $5 S$ has a direct and positive effect on SMED because when the first variable increases its standard deviation in one unit, the second one goes up 0.571 units.

Figure 2 shows that the dependent variables have associated an $\mathrm{R}^{2}$ value to measure the variance explained by the independent variables. However, it is unknown how much each independent variable contributes, called effect size (ES). For this reason, Table 5 illustrates the decomposition of this $\mathrm{R}^{2}$ value into its components, or the ES of each independent variable. The sum of the ES in a dependent variable is equal to the $\mathrm{R}^{2}$ value.

Table 5. Contribution of direct effects in $\mathrm{R}^{2}$.

\begin{tabular}{ccccc}
\hline & 5S & SMED & COF & $\mathbf{R}^{2}$ \\
\hline SMED & 0.327 & & & 0.327 \\
COF & 0.113 & 0.390 & 0.241 & 0.503 \\
ES & 0.098 & 0.124 & 0.463 \\
\hline
\end{tabular}

According to the information contained in Table 5, we can conclude the following:

- $\quad$ SMED is explained by $5 S$ by $32.7 \%$, and is the only variable that directly affects it.

- COF is explained as 50.3\%; however, 5 S contributes $11.3 \%$, and SMED contributes $39.0 \%$. Given that the SEMD contribution to explaining COF is bigger, then those values allow concluding that maquiladoras that wish to have a COF in their production lines should focus on having high levels of SMED implementation because that means low idle time for machinery.

- $\quad$ ES is explained as $46.3 \%$; however, 5 S contributes $9.8 \%$, SMED contributes $12.4 \%$, and COF contributes $24.1 \%$. Those values conclude that COF is the most critical variable in explaining ES, so maquiladoras should be concerned about maintaining their production lines with a continuous flow to be economically profitable, increasing financial income. However, SMED favors COF and 5S favors SMED, so a critical route for LM techniques supporting $\mathrm{ES}$ is as follows: $5 \mathrm{~S} \rightarrow \mathrm{SMED} \rightarrow \mathrm{COF} \rightarrow \mathrm{ES}$.

\subsubsection{Sum of Indirect and Total Effects}

Table 6 illustrates the sum of indirect and total effects, the associated p-values, and the effect size (ES) for every relationship. Observe that all direct and total effects are statistically significant, as the associated p-values are less than 0.05 in all cases.

Table 6. Sum of indirect and total effects.

\begin{tabular}{|c|c|c|c|}
\hline \multicolumn{4}{|c|}{ Sum of Indirect Effects } \\
\hline & $5 S$ & SMED & COF \\
\hline $\mathrm{COF}$ & $\begin{array}{c}\beta=0.324 p<0.001 \\
E S=0.174\end{array}$ & & \\
\hline ES & $\begin{array}{c}\beta=0.327 p<0.001 \\
E S=0.168\end{array}$ & $\begin{array}{c}\beta=0.218 p<0.001 \\
E S=0.126\end{array}$ & \\
\hline \multicolumn{4}{|c|}{ Total Effects } \\
\hline SMED & $\begin{array}{c}\beta=0.571 p<0.001 \\
E S=0.327\end{array}$ & & \\
\hline $\mathrm{COF}$ & $\begin{array}{c}\beta=0.535 p<0.001 \\
E S=0.286\end{array}$ & $\begin{array}{c}\beta=0.567 p<0.001 \\
E S=0.390\end{array}$ & \\
\hline ES & $\begin{array}{c}\beta=0.518 p<0.001 \\
E S=0.266\end{array}$ & $\begin{array}{c}\beta=0.432 p<0.001 \\
E S=0.250\end{array}$ & $\begin{array}{c}\beta=0.384 p<0.001 \\
E S=0.241\end{array}$ \\
\hline
\end{tabular}

There is a particular interest for the indirect effect between $5 \mathrm{~S} \rightarrow \mathrm{ES}$ since the direct effect was only 0.190 , but the indirect effect is 0.327 ; so, the indirect effect is $70 \%$ larger, indicating the importance of SMED and COF as mediating variables in that relationship. 
Something similar occurs with the indirect relationship between $5 \mathrm{~S} \rightarrow \mathrm{COF}$ since the direct effect is only 0.210 , but the indirect effect through SMED as a mediating variable is 0.327 , $55 \%$ larger.

\subsubsection{Sensitivity Analysis}

Table 7 illustrates the sensitivity analysis. High scenarios are indicated by the symbol " + ", and low scenarios are shown by "-". The joint probabilities in a combination of scenarios are represented by \& and the conditional probabilities by If. For example, 5S+ has an occurrence probability of 0.219 , but $5 S-$ has 0.124 . Additionally, the probability of finding 5S+ and SMED+ simultaneously in a production line is 0.083 , a shallow value, because managers prefer to have high values; however, if 5S+ has occurred, then there is a conditional probability of 0.378 of finding SMED+, indicating the dependence importance.

Table 7. Sensitivity analysis.

\begin{tabular}{|c|c|c|c|c|c|c|c|}
\hline Level & & $5 S+$ & $5 S_{-}$ & SMED+ & SMED- & $\mathrm{COF}+$ & $\mathrm{COF}-$ \\
\hline & Prob & 0.219 & 0.124 & 0.118 & 0.118 & 0.130 & \\
\hline SMED+ & 0.118 & $\begin{array}{l}\&=0.083 \\
\text { If }=0.378\end{array}$ & $\&=0.000$ & & & & \\
\hline SMED- & 0.118 & $\begin{array}{l}\&=0.012 \\
\text { If }=0.054\end{array}$ & $\begin{array}{l}\&=0.065 \\
\text { If }=0.524\end{array}$ & & & & \\
\hline $\mathrm{COF}+$ & 0.130 & $\begin{array}{l}\&=0.083 \\
\text { If }=0.378\end{array}$ & $\begin{array}{l}\&=0.000 \\
\text { If }=0.000\end{array}$ & $\begin{array}{l}\&=0.077 \\
\text { If }=0.650\end{array}$ & $\begin{array}{l}\&=0.000 \\
\text { If }=0.000\end{array}$ & & \\
\hline $\mathrm{COF}-$ & 0.160 & $\begin{array}{l}\&=0.012 \\
\text { If }=0.054\end{array}$ & $\begin{array}{l}\&=0.089 \\
\text { If }=0.714\end{array}$ & $\begin{array}{l}\&=0.006 \\
\text { If }=0.050\end{array}$ & $\begin{array}{l}\&=0.095 \\
\text { If }=0.800\end{array}$ & & \\
\hline $\mathrm{ES}+$ & 0.154 & $\begin{array}{l}\&=0.089 \\
\text { If }=0.405\end{array}$ & $\begin{array}{l}\&=0.006 \\
\text { If }=0.048\end{array}$ & $\begin{array}{l}\&=0.089 \\
\text { If }=0.750\end{array}$ & $\begin{array}{l}\&=0.006 \\
\text { If }=0.050\end{array}$ & $\begin{array}{l}\&=0.083 \\
\text { If }=0.636\end{array}$ & $\begin{array}{l}\&=0.006 \\
\text { If }=0.037\end{array}$ \\
\hline ES- & 0.166 & $\begin{array}{l}\&=0.024 \\
\text { If }=0.108\end{array}$ & $\begin{array}{l}\&=0.065 \\
\text { If }=0.524\end{array}$ & $\begin{array}{l}\&=0.012 \\
\text { If }=0.100\end{array}$ & $\begin{array}{l}\&=0.071 \\
\text { If }=0.600\end{array}$ & $\begin{array}{l}\&=0.006 \\
\text { If }=0.045\end{array}$ & $\begin{array}{l}\&=0.083 \\
\text { If }=0.519\end{array}$ \\
\hline
\end{tabular}

In addition, $5 \mathrm{~S}-$ never is associated with SMED+ because the probabilities are zero. In conclusion, investment in $5 \mathrm{~S}$ is a warranty for SMED in MI. All other relationships are described in the Conclusions section.

\section{Conclusions and Industrial Implications}

\subsection{Regarding the Structural Equation Model}

Regarding the hypotheses proposed in Figure 1, the following is concluded based on the $\beta$ and $p$-value associated with the direct effects.

$\mathrm{H}_{1}$. There is enough statistical evidence to state that $5 \mathrm{~S}$ has a direct and positive effect on SMED implementation in MI, since when the first variable increases its standard deviation by one unit, the second goes up by 0.571 units. This result indicates that activities focused on maintaining a clean work area, with tools in place and high standards regarding all tasks, facilitate quick changeovers in maquiladora production lines to move from one product to another. With these achievements, maquiladoras will have greater flexibility with customers, and small lots deliver more customized batches, giving them a competitive advantage.

$\mathrm{H}_{2}$. There is enough statistical evidence to state that $5 \mathrm{~S}$ has a direct and positive effect on implementing continuous flow in the MI, since when the first variable increases its standard deviation by one unit, the second goes up by 0.210 units. However, an indirect effect of 0.324 units through SMED as a mediating variable gives a total effect of 0.571 units. The above confirms that maintaining clean work areas, with tools in place and with high standards, allows generating a continuous flow in production lines of MI, reducing idle time in machinery.

$\mathrm{H}_{3}$. There is enough statistical evidence to state that SMED has a direct and positive effect on implementing continuous flow in the MI since when the first variable increases its standard deviation by one unit, the second goes up by 0.567 units. This result indicates 
that rapid changeovers in production lines to move from one product to another in the MI facilitate the continuous flow of materials, since less time is lost with machines and equipment stopped for setups.

$\mathrm{H}_{4}$. There is enough statistical evidence to state that the $5 \mathrm{~S}$ implementation has a direct and positive effect on economic sustainability in the MI since when the first variable increases its standard deviation by one unit, the second one goes up by 0.190 units. However, 5S also has an indirect effect on ES, through COF and SMED, of 0.327 units, which gives a total effect of 0.518 units. The above findings indicate that the MI focused on maintaining clean work areas, having work tools in place, and maintaining high standards obtain economic benefits, indicating the monetary importance of 5S. Additionally, here it is essential to mention the role of the mediating variables of COF and SMED since the indirect effect through them is bigger than that generated directly.

$\mathrm{H}_{5}$. There is sufficient statistical evidence to state that the SMED implementation has a direct and positive effect on economic sustainability in MI, since when the first variable increases its standard deviation by one unit, the second goes up by 0.214 units. However, COF has an indirect effect of 0.218 units, giving a total effect of 0.432 units. These results indicate that the rapid changeovers in the production lines generate an economic benefit to the maquiladoras. This is because machines and tools have higher use and a reduced idle time, and the OEE increases.

$\mathrm{H}_{6}$. There is enough statistical evidence to state that the COF implementation has a direct and positive effect on economic sustainability in MI, since when the first variable increases its standard deviation by one unit, the second increases it by 0.384 units. These results indicate that by having a COF in production lines, there are no inventories in the process. In addition, there is less waste, indicating that the machines and tools are in perfect condition, which translates into lower production costs.

\subsection{Regarding the Sensitivity Analysis}

Similarly, interpreting the sensitivity analysis, a manager can identify how low scenarios for variables are a risk or how favorable high scenarios obtain certain benefits. The following conclusions can be drawn:

- Managers should strive to achieve 5S+, which guarantees SMED+, COF+, and ES+ with a conditional probability of $0.378,0.378$, and 0.405 . These findings indicate that investing and obtaining 5S+ will facilitate the implementation of SMED, COF, and ES. Additionally, 5S+ is weakly associated with SMED-, COF- and ES-, since the occurrence probabilities are $0.0054,0.012$, and 0.108 , respectively.

- However, $5 \mathrm{~S}$ - is a significant risk for managers since the conditional probability of SMED-, COF- and ES- occurring is 0.524, 0.714, and 0.524, respectively. These findings indicate that $5 \mathrm{~S}-$ is a barrier to proper SMED implementation or rapid changeovers in production lines, slowing down the process of adapting them to start the production process of another product. Additionally, they decrease the constant materials flow, affecting the production costs and competitiveness in the MI.

- Managers should seek SMED+, since that facilitates obtaining COF+ and ES+ with a probability of 0.650 and 0.750 , respectively. The above indicates that proper SMED implementation favors $\mathrm{COF}$ in the production lines and undoubtedly generates an economic benefit to MI since it reduces machine idle times due to changes in the production system. In addition, SMED+ has no association with COF- and ES-, as the conditional probabilities are low, only 0.050 and 0.100 , respectively.

- However, SMED - is a risk for the production lines since it can generate COF - and ES- with a probability of 0.800 and 0.600 . These results indicate that low levels of SMED implementation can lead to a slow flow of materials in the production system and an increase in the production cost since there will be idle machines and some work in process. Similarly, SMED- is not associated with COF+ and ES+, as the conditional probabilities of occurrence are low, warranting the investment of resources by managers. 
- $\quad$ Likewise, having a COF+ in the production lines should be ensured, as it favors ES+ with a probability of 0.636 . However, managers should be careful not to have COF-, as that can generate ES- with a probability of 0.519.

As a general conclusion, it can be mentioned that LM tools associated with material flow, such as 5S, SMED, and continuous flow, are interrelated and have direct and total direct effects on economic sustainability in the MI. The findings indicate that implementing these LM tools is justified, as their implementation always offers benefits.

\section{Limitations and Future Research}

Lean manufacturing is a set of several tools; however, only three tools associated with materials flow in the production system have been analyzed in this study. Furthermore, the $R^{2}$ values for the dependent variables are less than one, indicating that other tools explain them and favor their implementation. In future work, the LM tools will be integrated according to the LM pillars and analyzed with second-order structural equation models, increasing the predictive capacity of the dependent variables, such as sustainability.

Author Contributions: Conceptualization, J.L.G.-A. and J.R.D.R.; methodology, J.L.G.-A. and C.S.R.; software, J.L.R. and E.J.M.; validation, C.J.L. and J.R.D.R.; formal analysis, J.L.G.-A. and M.A.R.M.; investigation, J.L.G.-A. and J.R.D.R.; resources, E.J.M. and M.A.R.M.; data curation, C.J.L.; writingoriginal draft preparation, J.L.G.-A.; writing—review and editing, J.L.R.; visualization, C.S.R.; supervision, J.L.G.-A.; project administration, J.R.D.R. All authors have read and agreed to the published version of the manuscript.

Funding: This research received no external funding.

Institutional Review Board Statement: Ethical review and approval were waived for this study, because Institutional Review Board Statement indicates that this research is based in an online survey and only requires to obtain an online consent from all responders and guarantee the anonymity for all of them.

Informed Consent Statement: Online informed consent has been obtained from all responders to publish their information; however, the anonymity of all respondents has always been preserved throughout the questionnaire. The databases that have been created with all answers given are entirely anonymous.

Data Availability Statement: The final dataset used for the structural equation model can be consulted at https:// doi.org/10.17632/tht522mbph.1, accessed on 16 June 2021.

Acknowledgments: The authors appreciate all managers and engineers who responded to the questionnaire. We hope that the findings here reported will be helpful in the production lines they manage.

Conflicts of Interest: The authors declare no conflict of interest.

\section{References}

1. Puche, J.; Costas, J.; Ponte, B.; Pino, R.; de la Fuente, D. The effect of supply chain noise on the financial performance of kanban and drum-buffer-rope: An agent-based perspective. Expert Syst. Appl. 2019, 120, 87-102. [CrossRef]

2. Birasnav, M.; Bienstock, J. Supply chain integration, advanced manufacturing technology, and strategic leadership: An empirical study. Comput. Ind. Eng. 2019, 130, 142-157. [CrossRef]

3. Garcia-Alcaraz, J.L.; Maldonado-Macias, A.A.; Hernandez-Arellano, J.L.; Blanco-Fernandez, J.; Jimenez-Macias, E.; Saenz-Diez Muro, J.C. The impact of human resources on the agility, flexibility and performance of wine supply chains. Agric. Econ. 2017, 63, $175-184$.

4. $\quad$ Alcaraz, J.L.G.; Hernández, F.A.M.; Tiznado, J.E.O.; Vargas, A.R.; Macías, E.J.; Lardies, C.J. Effect of quality lean manufacturing tools on commercial benefits gained by Mexican maquiladoras. Mathematics 2021, 9, 971. [CrossRef]

5. IMMEX. Monhtly Statistics Report_General Information about Maquiladoras; IMMEX: Ciudad Juárez, Mexico, 2021; pp. 1-3.

6. Palange, A.; Dhatrak, P. Lean manufacturing a vital tool to enhance productivity in manufacturing. Mater. Today Proc. 2021, 46, 729-736. [CrossRef]

7. Yadav, G.; Luthra, S.; Huisingh, D.; Mangla, S.K.; Narkhede, B.E.; Liu, Y. Development of a lean manufacturing framework to enhance its adoption within manufacturing companies in developing economies. J. Clean. Prod. 2020, 245, 118726. [CrossRef] 
8. Tekin, M.; Arslandere, M.; Etlioğlu, M.; Koyuncuoğlu, Ö.; Tekin, E. An Application of Smed and Jidoka in Lean Production. In Proceedings of the International Symposium for Production Research 2018; Durakbasa, N.M., Gencyilmaz, M.G., Eds.; Springer International Publishing: Cham, Germany, 2019; pp. 530-545.

9. Melton, T. The benefits of lean manufacturing: What lean thinking has to offer the process industries. Chem. Eng. Res. Des. 2005, 83, 662-673. [CrossRef]

10. Islam, A.S.M.T. End of the day, who is benefited by lean manufacturing? A dilemma of communication and pricing in buyersupplier relationship. Manuf. Lett. 2019, 21, 17-19. [CrossRef]

11. Saetta, S.; Caldarelli, V. Lean Production as a Tool for Green Production: The Green Foundry Case Study. Procedia Manuf. 2020, 42, 498-502. [CrossRef]

12. Bai, C.; Satir, A.; Sarkis, J. Investing in lean manufacturing practices: An environmental and operational perspective. Int. J. Prod. Res. 2019, 57, 1037-1051. [CrossRef]

13. Cherrafi, A.; Elfezazi, S.; Chiarini, A.; Mokhlis, A.; Benhida, K. The integration of lean manufacturing, six sigma and sustainability: A literature review and future research directions for developing a specific model. J. Clean. Prod. 2016, 139, 828-846. [CrossRef]

14. Ghobadian, A.; Talavera, I.; Bhattacharya, A.; Kumar, V.; Garza-Reyes, J.A.; O’Regan, N. Examining legitimatisation of additive manufacturing in the interplay between innovation, lean manufacturing and sustainability. Int. J. Prod. Econ. 2018, 219, 457-468. [CrossRef]

15. Varela, L.; Araújo, A.; Ávila, P.; Castro, H.; Putnik, G. Evaluation of the relation between lean manufacturing, industry 4.0, and sustainability. Sustainability 2019, 11, 1439. [CrossRef]

16. Burawat, P. The mediate effect of lean manufacturing on the relationship between transaformational leadership and sustainability performance in thai smes. Int. J. Appl. Eng. Res. 2017, 12, 11647-11657.

17. Kalyar, M.N.; Shafique, I.; Abid, A. Role of lean manufacturing and environmental management practices in eliciting environmental and financial performance: The contingent effect of institutional pressures. Environ. Sci. Pollut. Res. 2019, 26, 24967-24978. [CrossRef] [PubMed]

18. Shah, R.; Ward, P.T. Lean manufacturing: Context, practice bundles, and performance. J. Oper. Manag. 2003, 21, 129-149. [CrossRef]

19. Yang, M.G.; Hong, P.; Modi, S.B. Impact of lean manufacturing and environmental management on business performance: An empirical study of manufacturing firms. Int. J. Prod. Econ. 2011, 129, 251-261. [CrossRef]

20. Fullerton, R.R.; Kennedy, F.A.; Widener, S.K. Lean manufacturing and firm performance: The incremental contribution of lean management accounting practices. J. Oper. Manag. 2014, 32, 414-428. [CrossRef]

21. Aquilani, B.; Silvestri, C.; Ruggieri, A. Sustainability, TQM and value co-creation processes: The role of critical success factors. Sustainability 2016, 8, 995. [CrossRef]

22. Green, K.W.; Sower, V.E.; Zelbst, P.J.; Inman, R.A. Impact of JIT, TQM and green supply chain practices on environmental sustainability. J. Manuf. Technol. Manag. 2019, 30, 26-47. [CrossRef]

23. Yazdi, P.G.; Azizi, A.; Hashemipour, M. An empirical investigation of the relationship between overall equipment efficiency (OEE) and manufacturing sustainability in industry 4.0 with time study approach. Sustainability 2018, 10, 3031. [CrossRef]

24. Des Reis, M.D.O.; Godina, R.; Pimentel, C.; Silva, F.J.G.; Matias, J.C.O. A TPM strategy implementation in an automotive production line through loss reduction. Procedia Manuf. 2019, 38, 908-915. [CrossRef]

25. Setiawan, N.; Salleh, M.R.; Ariff, H.A.; Rahman, M.A.A.; Mohamad, E.; Sulaiman, M.A.; Zaini, F.F.; Ito, T. A proposal of performance measurement and management model for 5 s sustainability in manufacturing SMES: A review. J. Adv. Mech. Des. Syst. Manuf. 2021, 15, 1-15. [CrossRef]

26. Xu, Y.; Ramzan, S.; Munir, H.; Liu, C.; Gupta, B. The adoption of online e-waste collection platform to improve environmental sustainability: An empirical study of Chinese millennials. Manag. Environ. Qual. An. Int. J. 2020, 32, 193-209.

27. Jun, M.; Cai, S.; Shin, H. TQM practice in maquiladora: Antecedents of employee satisfaction and loyalty. J. Oper. Manag. 2006, 24, 791-812. [CrossRef]

28. García, J.L.; Rivera, L.; Blanco, J.; Jiménez, E.; Martínez, E. Structural equations modelling for relational analysis of JIT performance in maquiladora sector. Int. J. Prod. Res. 2014, 52, 4931-4949. [CrossRef]

29. Díaz-Reza, J.R.; García-Alcaraz, J.L.; Martínez-Loya, V.; Blanco-Fernández, J.; Jiménez-Macías, E.; Avelar-Sosa, L. The effect of smed on benefits gained in maquiladora industry. Sustainability 2016, 8, 1237. [CrossRef]

30. García-Alcaraz, J.L.; Martínez-Loya, V.; Díaz-Reza, J.R.; Blanco-Fernández, J.; Jiménez-Macías, E.; López, A.J.G. Effect of ICT integration on SC flexibility, agility and company' performance: The Mexican maquiladora experience. Wirel. Netw. 2020, 26, 4805-4818. [CrossRef]

31. Morales-García, A.S.; Díaz-Reza, J.R.; García-Alcaraz, J.L. Effect of TPM and OEE on the social performance of companies. In Studies in Computational Intelligence; Springer Science and Business Media Deutschland GmbH: Berlin, Germany, 2021; Volume 966, pp. 119-141.

32. Velázquez, L.; Munguía, N.; De Los Ángeles Navarrete, M.; Zavala, A. An overview of sustainability practices at the maquiladora industry in mexico. Manag. Environ. Qual. Int. J. 2006, 17, 478-489. [CrossRef]

33. Vega, N.E.M.; Borboa, V.S.F.; Quintana, D.S.Z.; Contreras, L.E.V. Assessing the effectiveness of integrating ergonomics and sustainability: A case study of a Mexican maquiladora. Int. J. Occup. Saf. Ergon. 2018, 25, 587-596. [CrossRef] 
34. Hadjimarcou, J.; Brouthers, L.E.; McNicol, J.P.; Michie, D.E. Maquiladoras in the 21st century: Six strategies for success. Bus. Horiz. 2013, 56, 207-217. [CrossRef]

35. Cruthirds, K.W.; Coyle, T.; Velasco, M.P.T.; Marquez, B.G. World class logistics—South of the border: An analysis of Mexican maquiladora environmentally responsible practices. Int. J. Product. Qual. Manag. 2015, 15, 285-308. [CrossRef]

36. Chetthamrongchai, P.; Jermsittiparsert, K. Impact of lean manufacturing practices on financial performance of pharmaceutical sector in Thailand. Syst. Rev. Pharm. 2019, 10, 208-217.

37. Fullerton, R.R.; Wempe, W.F. Lean manufacturing, non-financial performance measures, and financial performance. Int. J. Oper. Prod. Manag. 2009, 29, 214-240. [CrossRef]

38. Avelar-Sosa, L.; García-Alcaraz, J.L.; Vergara-Villegas, O.O.; Maldonado-Macías, A.A.; Alor-Hernández, G. Impact of traditional and international logistic policies in supply chain performance. Int. J. Adv. Manuf. Technol. 2014, 76, 913-925. [CrossRef]

39. Brito, M.; Gonçalves, M.A. Ergosmed: A methodology to reduce setup times and improve ergonomic conditions. In Advances in Intelligent Systems and Computing; Springer: Cham, Germany, 2020; Volume 1026, pp. 549-554.

40. Rodríguez-Méndez, R.; Sánchez-Partida, D.; Martínez-Flores, J.L.; Arvizu-Barrón, E. A case study: Smed \& JIT methodologies to develop continuous flow of stamped parts into ac disconnect assembly line in schneider electric Tlaxcala plant. IFAC Pap. 2015, $48,1399-1404$.

41. Singh, A.; Ahuja, I.S. Review of 5 s methodology and its contributions towards manufacturing performance. Int. J. Process. Manag. Benchmarking 2015, 5, 408-424. [CrossRef]

42. Ribeiro, I.M.; Godina, R.; Pimentel, C.; Silva, F.J.G.; Matias, J.C.O. Implementing TPM supported by 5 s to improve the availability of an automotive production line. Procedia Manuf. 2019, 38, 1574-1581. [CrossRef]

43. Veres, C.; Marian, L.; Moica, S.; Al-Akel, K. Case study concerning 5s method impact in an automotive company. Procedia Manuf. 2018, 22, 900-905. [CrossRef]

44. Jiménez, M.; Romero, L.; Fernández, J.; Espinosa, M.M.; Domínguez, M. Extension of the lean 5s methodology to $6 \mathrm{~s}$ with an additional layer to ensure occupational safety and health levels. Sustainability 2019, 11, 3827. [CrossRef]

45. Misiurek, K.; Misiurek, B. Improvement of the safety and quality of a workplace in the area of the construction industry with use of the 6s system. Int. J. Occup. Saf. Ergon. 2020, 26, 514-520. [CrossRef]

46. Gnanaguru, R.; Thirumurugan, R.; Rajendran, I. Investigation of green manufacturing in motor and pump industries through a system model 'green-6s'. In Proceedings of the 1st International Conference on Materials, Design and Manufacturing for Sustainable Environment, ICMDMSE 2020; Mohan, S., Shankar, S., Rajeshkumar, G., Eds.; Springer Science and Business Media Deutschland GmbH: Berlin, Germany, 2021; pp. 775-795. [CrossRef]

47. Sukdeo, N.; Ramdass, K.; Petja, G. Application of 7s methodology: A systematic approach in a bucket manufacturing organisation. South. Afr. J. Ind. Eng. 2020, 31, 178-193.

48. Mahlaha, K.; Sukdeo, N.; Mofokeng, V. A Lean 7s Methodology Framework to Improve Efficiency and Organizational Performance: A Review Study in an SME Organization. In Proceedings of the 10th Annual International IEOM Conference, IEOM 2020, Dubai, United Arab Emirates, 10-12 March 2020; IEOM Society: Dubai, United Arab Emirates, 2020; pp. 962-970. Available online: http:/ / www.ieomsociety.org/ieom2020/papers/34.pdf (accessed on 26 August 2021).

49. Díaz-Reza, J.R.; García-Alcaraz, J.L.; Mendoza-Fong, J.R.; Martínez-Loya, V.; Macías, E.J.; Blanco-Fernández, J. Interrelations among SMED stages: A causal model. Complexity 2017, 2017, 1-10. [CrossRef]

50. Brito, M.; Ramos, A.L.; Carneiro, P.; Gonçalves, M.A. Combining SMED methodology and ergonomics for reduction of setup in a turning production area. Procedia Manuf. 2017, 13, 1112-1119. [CrossRef]

51. Bandyopadhyay, P.K.; Naik, S.; Ganguly, K. Reduction of setup time through SMED approach: A case study in the pharmaceutical industry. Int. J. Appl. Manag. Sci. Eng. 2015, 2, 20. [CrossRef]

52. Moreira, A.C.; Garcez, P.M.T. Implementation of the single minute exchange of die (SMED) methodology in small to medium-sized enterprises: A Portuguese case study. Int. J. Manag. 2013, 30, 66-87.

53. Piñeiro, D.P.; Nikolakopoulou, A.; Jäschke, J.; Braatz, R.D. Self-optimizing control of a continuous-flow pharmaceutical manufacturing plant. IFAC-Pap. 2020, 53, 11601-11606.

54. Bezerra, M.A.; Lemos, V.A.; de Oliveira, D.M.; Novaes, C.G.; Barreto, J.A.; Alves, J.P.S.; Cerqueira, U.M.F.d.M.; Santos, Q.O.d.; Araújo, S.A. Automation of continuous flow analysis systems-A review. Microchem. J. 2020, 155, 104731. [CrossRef]

55. Sinha, S.K.; Majumdar, A. Economic sustainability benchmarking of environmental initiatives: A case of wastewater treatment plant. Benchmarking Int. J. 2021, 28, 2008-2022.

56. Jiang, Z.; Lyu, P.; Ye, L.; Zhou, Y.w. Green innovation transformation, economic sustainability and energy consumption during China's new normal stage. J. Clean. Prod. 2020, 273, 123044. [CrossRef]

57. Hami, N.; Muhamad, M.R.; Ebrahim, Z. The impact of sustainable manufacturing practices and innovation performance on economic sustainability. Procedia CIRP 2015, 26, 190-195. [CrossRef]

58. Zhang, X.; Ao, X.; Cai, W.; Jiang, Z.; Zhang, H. A sustainability evaluation method integrating the energy, economic and environment in remanufacturing systems. J. Clean. Prod. 2019, 239, 118100. [CrossRef]

59. Taucean, I.M.; Miclea, S.; Ivascu, L.; Negrut, M.L. Analysis of interrelationship for lean and sustainability principles and implications. In Advances in Intelligent Systems and Computing; Springer: Cham, Germany, 2021; Volume 1221, pp. $217-227$.

60. Sharma, K.M.; Lata, S. Effectuation of lean tool " $5 \mathrm{~s}$ " on materials and work space efficiency in a copper wire drawing micro-scale industry in India. Mater. Today Proc. 2018, 5, 4678-4683. [CrossRef] 
61. Singh, R.J.; Singh, A. 5s-A quality improvement tool for sustainable performance: Literature review and directions. Int. J. Qual. Reliab. Manag. 2017, 34, 334-361.

62. Vitayasak, S.; Pongcharoen, P.; Hicks, C. Robust machine layout design under dynamic environment:Dynamic customer demand and machine maintenance. Expert Syst. Appl. X 2019, 3, 100015.

63. Morales Garcia, A.S.; García-Alcaraz, J.L.; Martínez Hernández, F.A.; Díaz Reza, J.R. Validation of questionnaire to know the level of lean manufacturing implementation [In Spanish]. Mem. Congr. Int. Investig. Acad. J. 2020. Available online: https:/ / shorturl.at/xBDVZ (accessed on 29 August 2021).

64. Gagnon, J.; Raskin, M.; Remache, J.; Sack, B. The financial market effects of the federal reserve's large-scale asset purchases. 24th Issue Int. J. Cent. Bank. 2018, 7, 45-52.

65. Morales García, A.; García Alcaraz, J.; Díaz Reza, J. Survey: Effect of Lean Manufacturing Tools on the Company's Environmental Performance, Ciudad Juarez, Mexico. 2021. Available online: https:/ / doi.org/10.6084/m9.figshare.14462163.v1 (accessed on 30 August 2021).

66. Amelec, V. Improvements in the supply chain of an automotive company through the implementation of continuous flow. Adv. Sci. Lett. 2015, 21, 1416-1418. [CrossRef]

67. Girón, A.; Kazemikhasragh, A.; Cicchiello, A.F.; Panetti, E. Sustainability reporting and firms' economic performance: Evidence from Asia and Africa. J. Knowl. Econ. 2020, 1-19. [CrossRef]

68. García-Alcaraz, J.L.; Montalvo, F.J.F.; Avelar-Sosa, L.; Pérez de la Parte, M.M.; Blanco-Fernández, J.; Jiménez-Macías, E. The importance of access to information and knowledge coordination on quality and economic benefits obtained from six sigma. Wirel. Netw. 2020, 26, 5713-5726. [CrossRef]

69. IMMEX. Monthly Statistics Report_General Information about Maquiladoras-May 14, 2021; IMMEX: Ciudad Juárez, Chihuahua, Mexico, 2021; p. 4.

70. IMMEX. Weekly Statistics Rreport_General Information about Workforce in Maquiladoras—May 7, 2021; IMMEX: Ciudad Juárez, Chihuahua, Mexico, 2021; p. 4.

71. Kock, N. Warppls User Manual: Version 6.0; ScriptWarp Systems: Laredo, TX, USA, 2017.

72. Hair, J.; Hult, G.; Ringle, C.; Sarstedt, M. A Primer on Partial least Square Structural Equation Modeling (PLS-SEM), 2nd ed.; Sage: Thousand Oaks, CA, USA, 2017; Volume 2.

73. Kock, N. Common method bias in pls-sem: A full collinearity assessment approach. Int. J. e-Collab. 2015, 11, 1-10. [CrossRef]

74. Iacobucci, D.; Posavac, S.S.; Kardes, F.R.; Schneider, M.J.; Popovich, D.L. Toward a more nuanced understanding of the statistical properties of a median split. J. Consum. Psychol. 2015, 25, 652-665. [CrossRef]

75. Teo, T.; Tsai, L.T.; Yang, C.-C. Applying structural equation modeling (SEM) in educational research. In Application of Structural Equation Modeling in Educational Research and Practice; Khine, M.S., Ed.; Sense Publishers: Rotterdam, The Netherlands, 2013; pp. 3-21.

76. Westland, J.C. Partial least squares path analysis. In Structural Equation Models: From Paths to Networks; Westland, J.C., Ed.; Springer International Publishing: Cham, Germany, 2019; pp. 17-38.

77. Hernández, F.A.M.; Alcaraz, J.L.A. Survey to Determine the Level of Implementation of Lean Manufacturing Practices. figshare 2021. Available online: https:/ / figshare.com/articles/dataset/_/14301275 (accessed on 30 August 2021). 